of male tissue. The fact that they were completely normal as to sex suggested that the exceptional area was haploid in constitution, the complex, $1 X: 1 A$, being known to be female. In addition, the exceptional tissue showed the greatly reduced size of bristles, eye-facets and wing-cells characteristic of haploid tissue. To test this hypothesis, a series of matings was made in which the autosomes as well as the $X$-chromosomes were differently marked in the two parents. Six more mozaics, all female, were obtained, and in each of these the genome of the father only was manifested in the exceptional region. This result suggests that the basis of mozaicism in these flies is some peculiarity following fertilization which permits of a division of the sperm nucleus before the fusion with the egg-nucleus becomes complete, so that a group of haploid cells is formed bearing the paternal genome which eventually form part of the adult fly. (There is also evidence that two separate sperms occasionally take part in development and also that two female pronuclei are sometimes involved, but the mozaics resulting from these contingencies are extremely rare, and are not here considered.)

The importance of these 'merogonic' mozaics lies in the opportunity they may give of studying the maturation processes of haploid germ-cells where the possibility of normal conjugation is absent. That maturation does take place under these conditions is strongly suggested by the breeding results of one of the few mozaics obtained, in which the haploid tissue formed half the abdomen. Her progeny included six patroclinous sterile sons. These were almost certainly not the result of either primary or secondary non-disjunction since our other work on non-disjunctional forms of this species shows that such males are produced in this way only, with the greatest rarity. From their occurrence it is therefore inferred that the haploid germ-cells had undergone meiosis, which had resulted in the formation of some gametes containing all the autosomes but no $X$ chromosome. Such no- $X$ eggs if fertilized by $X$-sperm would give patroclinous sons lacking a $Y$ and therefore sterile. Moreover, these would form the only class recognizable as to their origin from the haploid or diploid tissue since, when the $X$ as well as the autosomes was included in such gametes at maturation, they could only give rise to offspring of regular phænotype. The exceptional sons therefore probably represent about a quarter of the actual number of gametes capable of producing viable zygotes that had been elaborated from the haploid tissue of this mozaic. As in the case of triploids, there were probably many more gametes, anuploid as to their main autosomes, and hence giving inviable zygotes.

If these conclusions are substantiated by cytological observation on future cases, it will be clear that conjugation itself, or the presence of a chromosome complex capable of conjugation, though indispensable in the diploid germ-cell as a means of orderly segregation, is not, as such, a necessary step in the process of maturation. The lack of it could not therefore be plausibly invoked as an explanation of the failure of maturation to be initiated or to reach completion in species hybrids.

Institute of Animal Genetics,

University of Edinburgh.

F. A. E. CREW. Rowena Lamy.

\section{Staunton on the Wax Insect of China}

Sir G. Staunton in his travels, "Embassy to China", published in 1797 in three volumes, describes, in vol. 1 on p. 352 , a wax-producing insect that he observed in Cochin-China and not in China proper. He says, "These insects, each not much exceeding the size of the domestic fly, were of a curious structure, having pectinate appendages rising in a curve, bending towards the head, not unlike the form of the tail feathers of the common fowl, but in the opposite direction. Every part of the insect was . . . completely covered with a white powder. The particular stem, frequented by these insects, was entirely whitened by a powder ... strewed upon it by them. The annexed engraving

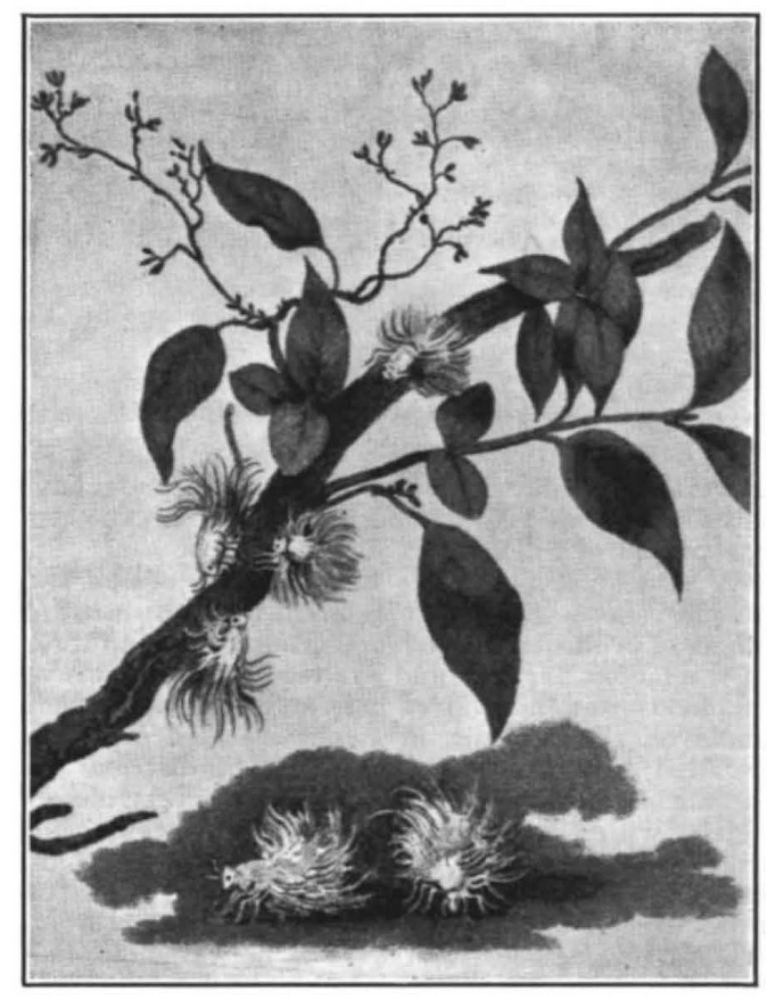

will convey some idea of what is here very imperfectly described. The powder was supposed to form the white wax of the East". He says further it is mixed with oils and moulded into candles.

Blanchard, in his "Coccides utiles", 1883, cites Staunton's work in his bibliography pertaining to the real Chinese wax insect, Ericerus pela. The engraving of Staunton, reproduced herewith, leaves no room for mistaking his insect for a scale insect, and it is surprising how Blanchard was led into such an error. Through the kindness of the British Consul-General in Chung King, I have been able to obtain some of the Chinese wax insects, which are entirely unlike the species illustrated by Staunton. It seems to me that the insect illustrated by him is probably a Cicad of the family Flatidæ, and what he saw may have been the larvæ of this unknown Cicad.

\section{S. Mahdirassan.}

Leipzig. 